\title{
Do Chenopodium ambrosioides-Synthesized Silver Nanoparticles Impact Oryzias melastigma Predation Against Aedes albopictus Larvae?
}

\author{
Jayapal Subramaniam ${ }^{1,2}$ - Kadarkarai Murugan ${ }^{2,3}$ • \\ Arulsamy Jebanesan' ${ }^{1}$ Philips Pontheckan ${ }^{2}$. \\ Devakumar Dinesh ${ }^{2} \cdot$ Marcello Nicoletti $^{4}$. \\ Hui Wei ${ }^{5}$ Akon Higuchi' ${ }^{6}$ Suresh Kumar ${ }^{7}$. \\ Angelo Canale ${ }^{8} \cdot$ Giovanni Benelli $^{8}$
}

Received: 23 October 2016/Published online: 7 November 2016

(C) Springer Science+Business Media New York 2016

\begin{abstract}
The green synthesis of nanopesticides has been recently proposed to improve the efficacy of mosquito control programs. However, limited efforts shed light on the impact of sub-lethal doses of nanopesticides on behavioral traits of mosquito biocontrol agents. We described the synthesis of silver nanoparticles (AgNP) at room temperature using the aqueous extract of Chenopodium ambrosioides, and their high toxicity against the invasive mosquito Aedes albopictus. $\mathrm{LC}_{50}$ calculated on young instars ranged from $13 \mathrm{ppm}$ (first instar larvae) to $19 \mathrm{ppm}$ (pupae). $\mathrm{LC}_{50}$ calculated on adults was $14 \mathrm{ppm}$. The chemical composition of the $C$. ambrosioides extract was characterized by GC-MS analysis. The production of
\end{abstract}

Giovanni Benelli

benelli.giovanni@gmail.com

1 Divison of Vector Biology and Control, Department of Zoology, Faculty of Science, Annamalai University, Annamalai Nagar, Chidambaram, Tamil Nadu 608 002, India

2 Division of Entomology, Department of Zoology, School of Life Sciences, Bharathiar University, Coimbatore, Tamil Nadu 641046, India

3 Department of Biotechnology, Thiruvalluvar University, Serkkadu, Vellore, Tamil Nadu 632115, India

4 Department of Environmental Biology, Sapienza University of Rome, Piazzale Aldo Moro 5, 00185 Rome, Italy

5 Institute of Plant Protection, Fujian Academy of Agricultural Sciences, 247 Wusi Road, Fuzhou 350003, China

6 Department of Chemical and Materials Engineering, National Central University, No. 300, Jhongli, Taoyuan 32001, Taiwan

7 Department of Medical Microbiology and Parasitology, Universiti Putra Malaysia UPM, 43400 Serdang, Selangor, Malaysia

8 Department of Agriculture, Food and Environment, University of Pisa, Via Del Borghetto 80, 56124 Pisa, Italy 
AgNP was confirmed by the surface Plasmon resonance band illustrated in UV-Vis, FTIR spectroscopy, EDX, XRD, TEM, and Zeta Potential analyses. In the field, a single treatment of $\mathrm{AgNP}\left(10 \times \mathrm{LC}_{50}\right)$ led to complete elimination of larval populations within $72 \mathrm{~h}$. Sub-lethal doses of the reducing extract and AgNP magnify predation rates of Oryzias melastigma fishes against A. albopictus larvae. Overall, this study highlights the concrete potential of C. ambrosioides-synthesized AgNP to develop effective and cheap tools to control young instars and adults of the invasive mosquito A. albopictus.

Keywords Biological control · Biosafety · Larvivorous fishes ·

Nanobiotechnology $\cdot$ Nanocrystals

\section{Introduction}

Mosquitoes represent a major public health problem, since they act as vectors of serious diseases, including malaria, yellow fever, West Nile virus, filariasis, Japanese encephalitis, dengue and chikungunya [9, 15, 74, 75]. Dengue is an emerging disease, currently considered the most important arbovirus in the world. Aedes mosquitoes mainly vector it. Dengue slyly arrived in the Western Hemisphere over decades, and then its incidence has grown dramatically from the 1990s. The actual numbers of dengue cases are underreported and many cases are misclassified $[14,47,134]$. WHO estimates that dengue infects about 400 million people annually in the part of tropical and subtropical regions [18, 20, 134]. Very recently, mosquito from the Aedes genus also vectored Zika virus to people [135], leading to outbreaks in the Americas, and the Pacific area. Zika symptoms are similar to other arbovirus infections such as dengue, and include fever, skin rashes, conjunctivitis, muscle and joint pain, malaise, and headache. These symptoms normally last for 2-7 days and can be followed by neurological complications and malformations in neonates [37, 135]. Although there are several potential dengue vectors, the field isolation of viruses and epidemiological evidence show that Aedes aegypti and A. albopictus are the main vectors [14]. A. albopictus, also known as the Asian tiger mosquito, originates in Asia and also serves as a vector of chikungunya and many other arboviruses [57, 59, 129].

The use of chemicals insecticides in routine mosquito control operations led to the development of resistance in the targeted vector species [55, 91], as well as to detrimental effects on non-target organisms, with special reference to biological control agents such as larvivorous fishes and other important aquatic predators of Culicidae [26, 96, 105, 112]. Therefore, plant-based insecticides may serve as suitable alternative to synthetic molecules as they are environmentally safe, biodegradable, and are easily available in all parts of the world [4, 10, 16, 53, 124]. In addition, it is worthy to note that the toxicity of botanical-based biopesticides such as plant extracts and essential oils is usually exerted by multiple mechanisms of action, lowering the chances of resistance development in targeted arthropods [99]. 
Recently, silver nanoparticles (AgNP) gained a focus of intensive research owing to their wide range of applications in areas such as catalysis, optics, antimicrobials, pesticides, biomedical and biomaterial production [7, 39, 64, 126]. The biological synthesis of metal nanoparticles is a research area currently considered more ecofriendly and cost-effective, if compared to other chemical and physical methods $[3,11]$. Nano-technology is envisaged to be the next frontier in the ongoing development of cancer therapy [22, 35] as researchers in the biomedical and material engineering fields are working together to discover the possibility of using nano-materials as novel tools for medical sciences. In particular, a number of approaches are available for the synthesis of silver nanoparticles, such as thermal decomposition [93], electrochemical [121], microwave-assisted process [120] and green chemistry $[8,12]$.

Phytochemicals have a major role in current mosquito control research [9, 10]. Plant extracts have been used as reducing and capping agent for the synthesis of nanoparticles. Indeed, the latter is advantageous over photochemical reduction, heat evaporation, electrochemical reduction, and chemical reduction methods [11]. Because of such a wide range of applications, numerous methods concerning the fabrication of AgNP, as well as various silver-based compounds containing ionic silver $\left(\mathrm{Ag}^{+}\right)$or metallic silver $\left(\mathrm{Ag}^{0}\right)$ have been developed. The synthetic methods used for the preparation of AgNP rely to some toxic chemical used as reducing agents such as $\mathrm{NaBH}_{4}$, citrate or ascorbate. On the other hand, in plant-mediated reducing processes leading to the production of nanoparticles, no chemical reagent or surfactant template is required, which consequently enables the bioprocess with the advantage of being eco-friendly [13, 87-90].

Another important challenge for mosquito control is the successful implementation of biological control programs. Indeed, the natural enemies feeding on mosquito larvae and pupae in aquatic environments play an important role in reducing Culicidae populations (e.g. [65, 131, 136]. Larvivorous fishes are being successfully exploited for control of mosquito vectors aquatic stages in European, Asian, African and Arabian countries [21, 65]. Moreover, the larvivorous fishes provide dual benefits by reducing the mosquito populations and indirectly augmenting the aqua cultural economics [26, 73, 114, 132]; see [17] for a recent review).

Oryzias melastigma [72] (Beloniformes: Adrianichthyidae) [60] is a tiny cyprinodontid fish. It is a carnivorous, surface feeder found in both lentic and lotic waters. This semitransparent and hardy fish can tolerate a wide range of salinity [68], temperature, and many other adverse water qualities. Popularly known as rice fish orminnow [108] or Indian Medaka, or Bechi, it is a sexually dimorphic species [69]. It is found in limited areas of West Bengal, Tamil Nadu, Kerala, Orissa $[60,70]$ in India and also some riverine areas of Bangladesh.

Chenopodium ambrosioides Linn. (Chenopodiaceae) is widely distributed throughout India. Leaves are useful in the cure of influenza, pneumonia, typhoid and also as vermicide $[32,77]$. Chenopodium oil is a mixture ascaridole $(55.38 \%)$, p-cymene $(16.2 \%)$, alpha-terpinene $(9.7 \%)$, isoascaridole $(4.3 \%)$ and limonene (3.8\%) [24]. By contrast, little is known about the chemical composition of the polar extracts from $C$. ambrosioides. Nowadays, this species can be occasionally found 
also in pathways and near home gardens. It has diverse pharmacological applications in the treatment of influenza, cold or gastrointestinal and respiratory ailments, as well as vomiting, antihelmintic, healing of skin ulceration caused by Leishmania species, anti-inflammatory and antitumor properties [23, 38, 62, 92].

Even if the green synthesis of nanopesticides has been recently proposed to improve the efficacy of mosquito control programs [11], only limited efforts shed light on the potential impact of sub-lethal doses of nanopesticides on behavioral traits of mosquito biological control agents [82-84, 87-89, 127]. Here, we described the synthesis of AgNP at room temperature using the extract of $C$. ambrosioides as a reducing and capping/stabilizing agent, and their high toxicity against larvae, pupae and adults of the invasive mosquito Ae. albopictus. The chemical composition of the C. ambrosioides extract was characterized by GC-MS analysis. The effective production of AgNP was confirmed UV-Vis and FTIR spectroscopy, EDX, XRD, TEM, and Zeta Potential analysis. In the final experiments, the impact of sub-lethal doses of the reducing extract and AgNPs on predation rates of $O$. melastigma fishes against $A$. albopictus larvae was evaluated.

\section{Materials and Methods}

\section{Collection of Plant Materials}

C. ambrosioides plants used in this study were collected from the villages of The Nilgris, (Western Ghats of South India) Tamil Nadu, India. The plants were authenticated at Botanical Survey of India. Voucher specimens were deposited at Zoology Department, Bharathiar University, Coimbatore, India (Voucher ID n. CHENO-03).

\section{Mosquito Rearing}

Eggs of Ae. albopictus were provided by the National Centre for Disease Control (NCDC) field station of Mettuppalayam (Tamil Nadu, India). Eggs were transferred to laboratory conditions [27 $\pm 2{ }^{\circ} \mathrm{C}, 75-85 \%$ R.H., 14:10 (L:D) photoperiod] and placed in $18 \times 13 \times 4 \mathrm{~cm}$ plastic containers containing $500 \mathrm{~mL}$ of tap water, to await larval hatching $[41,128]$. Larvae were reared in these containers and fed daily with a mixture of crushed dog biscuits (Pedigree, USA) and hydrolyzed yeast (Sigma-Aldrich, Germany) at a 3:1 ratio (w:w). Water was renewed every 2 days. The breeding medium was checked daily and dead individuals were removed. Breeding containers were kept closed with muslin cloth to prevent contamination by foreign mosquitoes. Pupae were collected daily from culture containers and transferred to glass beakers containing $500 \mathrm{~mL}$ of water. Each glass beaker contained about 50 mosquito pupae and was placed in a mosquito-rearing cage $(90 \times 90 \times 90 \mathrm{~cm}$, plastic frames with chiffon walls) until adult emergence. Mosquito adults were continuously provided with $10 \%$ (w:v) glucose solution on cotton wicks. The cotton was always kept moist with the solution and changed daily. Five days after emergence, females were supplied with a blood meal which was 
furnished by means of professional heating blood (lamb blood), at a fixed temperature of $38{ }^{\circ} \mathrm{C}$ and enclosed in a membrane of cow gut. After $30 \mathrm{~min}$, the blood meal was removed and a fresh one was introduced [86, 95].

\section{C. ambrosioides-Mediated Synthesis of Silver Nanoparticles}

The $C$. ambrosioides aqueous leaf extract was prepared by adding $10 \mathrm{~g}$ of washed and finely cut leaves in a 300-mL Erlenmeyer flask filled with $100 \mathrm{~mL}$ of sterilized double distilled water, then boiling the mixture for $5 \mathrm{~min}$ before decanting it. The extract was filtered using Whatman filter paper n. 1, was stored at $-4{ }^{\circ} \mathrm{C}$ and tested within 5 days. The filtrate was treated with aqueous $1 \mathrm{mM} \mathrm{AgNO}_{3}$ (Precision Scientific Co., Coimbatore, India) solution in an Erlenmeyer flask and incubated at room temperature [82]. A dark brown solution indicated the formation of AgNP, as aqueous silver ions were reduced by the $C$. ambrosioides extract generating stable AgNP in water.

\section{GC-MS Analysis}

GC-MS analysis of the plant ethanolic extract was performed using a Perkin Elmer GC Claurus 500 system and Gas Chromatograph interfaced to a Mass Spectrometer (GC/MS) equipped with a Elite-1 fused silica capillary column $(30 \mathrm{~m} \times 0.25 \mathrm{~mm}$ ID. $\times 1 \mu \mathrm{Mdf}$, composed of $100 \%$ Dimethyl poly siloxane). The plant ethanolic extract was prepared following the method by [98]. For GC-MS detection, an electron ionization system with ionization energy of $70 \mathrm{eV}$ was used. Helium gas $(99.999 \%)$ was used as the carrier gas at a constant flow rate of $1 \mathrm{ml} / \mathrm{min}$. and an injection volume of $2 \mu \mathrm{l}$ was employed (split ratio of 10:1). The injector temperature was $250{ }^{\circ} \mathrm{C}$. The ion-source temperature was $280{ }^{\circ} \mathrm{C}$. The oven temperature was programmed from $110{ }^{\circ} \mathrm{C}$ (isothermal for $2 \mathrm{~min}$.), with an increase of $10{ }^{\circ} \mathrm{C} / \mathrm{min}$, to $200{ }^{\circ} \mathrm{C}$, then $5{ }^{\circ} \mathrm{C} / \mathrm{min}$ to $280{ }^{\circ} \mathrm{C}$, ending with a $9 \mathrm{~min}$. isothermal at $280{ }^{\circ} \mathrm{C}$. Mass spectra were taken at $70 \mathrm{eV}$; a scan interval of $0.5 \mathrm{~s}$ and fragments from 45 to $450 \mathrm{Da}$. Total $\mathrm{GC}$ running time was $36 \mathrm{~min}$. The relative percentage amount of each component was calculated by comparing its average peak area to the total areas. Software adopted to handle mass spectra and chromatograms was a TurboMass Ver 5.2.0 [130].

\section{Characterization of Silver Nanoparticles}

C. ambrosioides-synthesized AgNP were characterized by UV-Vis spectrophotometry, FTIR spectroscopy, TEM, EDX, XRD and Zeta potential analysis [85, 107]. In $\mathrm{UV}-\mathrm{V}$ is absorbance spectrophotometry, the bio-reduction of $\mathrm{AgNO} 3$ in the aqueous medium was monitored by periodic sampling of aliquots $(2 \mathrm{~mL})$, measuring the $\mathrm{UV}-\mathrm{V}$ is spectrum in $10 \mathrm{~mm}$ quartz cuvette with a systronics. We used a UV-Vis spectrophotometer (Hewlett-Packard diode array spectrophotometer, model HP8452 , resolution: $1 \mathrm{~nm}$ ) operating at 500 and $680 \mathrm{~nm}$ with a scanning speed of $1856 \mathrm{~nm} / \mathrm{min}$. OD values were recorded until 3 days after biosynthesis at regular intervals. Samples were centrifuged at 42,000 rpm for $10 \mathrm{~min}$; pellets were dried; 
and the nano-powder obtained was used for further analyses. TEM was performed using a JEOL model $1200 \mathrm{EX}$ instrument operating at an accelerating voltage of $120 \mathrm{kV}$. Samples were prepared by placing tiny drops of AgNP solutions on carboncoated TEM grids. The film on the TEM grid was allowed to dry for 5 min under laboratory conditions. XRD analysis of drop-coated films on glass substrates from the AOT-capped AgNP was carried out on a Phillips PW1830 instrument operating at $40 \mathrm{kV}$ and a current of $30 \mathrm{~mA}$ with $\mathrm{Cu} \mathrm{K}_{\alpha}$ radiation. EDX analyzed the presence of metals in the sample (JEOL-MODEL 6390); the XRD patterns were phase matched using match software version 1.10c Inc. Standard values are obtained from the International Centre for Diffraction Data ICDD. Hkl indices and the mean size of AgNP were calculated using the Debye-Scherer equation by determining the width of (111) and similar Bragg's reflection parameters [83]. For FTIR measurements, samples were prepared as described for XRD analysis, and measured using a Shimadzu $8400 \mathrm{~s}$ with spectral range of $4000-400 \mathrm{~cm}^{-1}$ and resolution of $4 \mathrm{~cm}^{-1}$. FTIR spectra of leaf extracts sampled before and after the biosynthesis of AgNP were compared to examine possible functional groups involved in AgNP formation [41, 126].

\section{Larvicidal Activity Against A. albopictus}

Following the methods reported by [128], 25 mosquito larvae (I, II, III or IV instar) or pupae were placed for $24 \mathrm{~h}$ in a $500-\mathrm{mL}$ glass beaker filled with dechlorinated water plus $C$. ambrosioides leaf ethanolic extract (80, 160, 240, 360 and 400 ppm) or C. ambrosioides-synthesized AgNP (10, 20, 30, 40 and $50 \mathrm{ppm}$ ). Larval food $(0.5 \mathrm{mg})$ was provided for each tested concentration. Each concentration was replicated 5 times against all instars. In the control, 25 larvae or pupae were transferred to $250 \mathrm{~mL}$ of dechlorinated water. No mortality was observed in the control. Percentage mortality was calculated as follows:

Percentage mortality $=($ number of dead individuals $/$ number of treated individuals $)$ * 100.

\section{Larvicidal Activity in the Field}

C. ambrosioides ethanolic extract and C. ambrosioides-synthesized AgNP were applied in six external water storage reservoirs in each of two field sites at the National Institute of Communicable Disease Centre (Coimbatore, India).Treatments were carried out using a knapsack sprayer (Private Limited 2008, Ignition Products, India) [82]. Pre-treatment Aedes larval density was monitored. Post-treatment observations were conducted after 24,48 and $72 \mathrm{~h}$, using a larval dipper. Toxicity was assessed against third- and fourth instars larvae. Six trials were conducted for each test site with similar weather conditions $\left(28 \pm 2{ }^{\circ} \mathrm{C} ; 80 \%\right.$ R.H. $)$. The required 
quantity of mosquitocide was calculated on the basis of the total surface area and volume (i.e. $0.25 \mathrm{~m}^{3}$ and $250 \mathrm{~L}$ for all sites). Then, the required concentration was prepared using $10 \times \mathrm{LC}_{50}$ values [80, 128]. Percentage reduction of the larval density was calculated using the formula:

\section{Percentage reduction $=(\mathrm{C}-\mathrm{T}) / \mathrm{C} \times 100$}

where $\mathrm{C}$ is the total number of mosquitoes in the control, and $\mathrm{T}$ is the total number of mosquitoes in the treatment [126].

\section{Adulticidal Activity}

Adulticidal experiments were performed following the methods reported by the [126, 127, 133]. C. ambrosioides ethanolic leaf extract was tested at 60, 120, 180, 240 and $300 \mathrm{ppm}$. AgNP were tested at 6, 12, 18, 24 and $30 \mathrm{ppm}$ formulated in $5 \mathrm{~mL}$ of aqueous solution. C. ambrosioides aqueous extract and AgNP were applied on Whatman n. 1 filter paper (size $12 \times 15 \mathrm{~cm}$ ) lining a glass holding tube (diameter $30 \mathrm{~mm}$; length $60 \mathrm{~mm}$ ). In control treatments, filter papers were treated with either the same volume of distilled water plus ethanol or $\mathrm{AgNO}_{3}(1 \mathrm{mM})$ in aqueous solution. In each test, $20 \mathrm{~A}$. albopictus females were gently transferred into another glass holding tube. The mosquitoes were allowed to acclimatize in the tube for $1 \mathrm{~h}$ and then exposed to a test tube lined with treated or control paper for $1 \mathrm{~h}$. At the end of exposure period, the mosquitoes were transferred back to the original holding tube, kept for a $24 \mathrm{~h}$ recovery period and then mortality was recorded. A pad of cotton soaked with $10 \%(\mathrm{w}: \mathrm{v})$ glucose solution was placed on the mesh screen at the top of the holding tube [126].

\section{Oryzias melastigma Predation on A. albopictus Larvae}

O. melastigma fishes were collected from Tamil Nadu Fisheries Department, Mettur Dam, Salem, and maintained in cement tanks $(120 \mathrm{~cm}$ diameter and $60 \mathrm{~cm}$ depth) containing field collected water at $27 \pm 3{ }^{\circ} \mathrm{C}$ and external RH 85\%. For the assays, the predatory fishes were released in separate transparent containers $(14 \times 10 \mathrm{~cm})$ containing clean water. The predatory efficiency of $O$. melastigma was assessed against II and III instar larvae of $A$. albopictus. In each trial, 200 mosquito larvae were introduced, with 1 adult $O$. melastigma, in plastic cups $(2 \mathrm{~L})$ containing dechlorinated water. For each tested mosquito instar, five replicates were conducted. Control was $2 \mathrm{~L}$ of dechlorinated water plus 200 larvae, without $O$. melastigma. All experimental cups checked after $24 \mathrm{~h}$ and the number of dead/preys consumed by predator was recorded. After each checking, the predated mosquito larvae were replaced with new ones. Similarly, five replicates were made for each prey density with predators or without predators (control), before and after the treatment of the leaf extract or AgNP. Using the same fish, the rate of predation was observed for five consecutive days. The prey density was set to same value after every $24 \mathrm{~h}$. The fish predatory efficiency was calculated using the following formula: 
Predatory efficiency $=[$ (number of consumed mosquitoes $/$ number of predators $)$ $/$ total number of mosquitoes $] \times 100$

\section{Oryzias melastigma Predation on A. albopictus Larvae Post-Treatment with Ag Nanoparticles.}

Here, 200 mosquito larvae were introduced, with 1 adult $O$. melastigma; in plastic cups $(2 \mathrm{~L})$ containing dechlorinated water plus $1 / 3$ of the $\mathrm{LC}_{50}$ calculated against III and IV instar larvae of $A$. albopictus $[82,83]$. For each tested mosquito instar, five replicates were conducted. Control was $2 \mathrm{~L}$ of AgNP-contaminated water plus 200 larvae, without predator fish $(O$. melastigma). All experimental cups checked after $24 \mathrm{~h}$ and the number of preys consumed by $O$. melastigma was recorded. After each checking, the predated mosquito larvae were replaced with new ones. Similarly, five replicates were made for each prey density with predators or without predators (control), before and after the treatment of the leaf extract or AgNP. Using the same predator individual, the rate of predation was observed for five consecutive days. The prey density is being set to same value after every $24 \mathrm{~h}$. The fish predatory efficiency was calculated using the above-mentioned formula.

\section{Data Analysis}

Mosquito mortality data from laboratory assays were analyzed by probit analysis, calculating $\mathrm{LC}_{50}$ and $\mathrm{LC}_{90}$ following the method by [44]. Mosquito larval density data from field assays were analyzed using a two-way ANOVA with two factors (i.e. the mosquitocidal treatment and the elapsed time from treatment). In all analyses, a probability level of $\mathrm{P}<0.05$ was used for the significance of differences among values.

O. melastigma predation data were analyzed using a weighted general linear model with two fixed factors: $y=X \beta+\varepsilon$, where $y$ is the vector of the observations (the number of consumed preys), $X$ is the incidence matrix, $\beta$ is the vector of fixed effects (treatment and targeted mosquito instar), and $\varepsilon$ is the vector of the random residual effect. A probability level of $\mathrm{P}=0.05$ was used for the significance of differences between values.

\section{Results and Discussion}

\section{Chemical Composition of $C$. ambrosioides Leaf Extract}

The interpretation on mass spectrum GC-MS was conducted using the database of National Institute Standard and Technology (NIST) having more than 62,000 patterns. The spectrum of the unknown component was compared with the spectrum of the known components stored in the NIST library. The name, molecular weight 


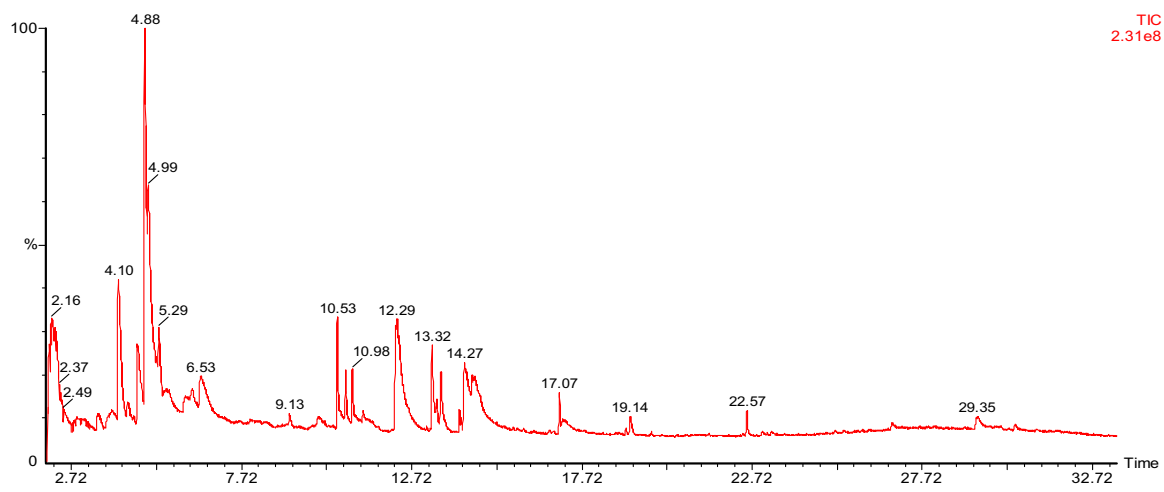

Fig. 1 GC-MS analysis of the Chenopodium ambrosioides leaf ethanolic extract

Table 1 Components identified in ethanolic extract of Chenopodium ambrosioides

\begin{tabular}{|c|c|c|c|c|c|}
\hline $\mathrm{N}$. & $\begin{array}{l}\mathrm{RT} \\
(\mathrm{min})\end{array}$ & Compounds & Formula & MW & $\begin{array}{l}\text { Peak } \\
\text { Area (\%) }\end{array}$ \\
\hline 1 & 4.10 & Bicyclo[4.1.0] heptan-3-ol, 4,7,7-trimethyl-( $1 \alpha, 3 \alpha, 4 \alpha, 6 \alpha)$ - & $\mathrm{C}_{10} \mathrm{H}_{18} \mathrm{O}$ & 154 & 13.28 \\
\hline 2 & 4.88 & 3-Methoxysalicylic acid & $\mathrm{C}_{8} \mathrm{H}_{8} \mathrm{O}_{4}$ & 168 & 18.38 \\
\hline 3 & 5.29 & $\begin{array}{l}\text { 7-Oxabicyclo[4.1.0] heptane, 1-methyl-4-(2- } \\
\text { methyloxiranyl)-( } \alpha \text {-Limonene diepoxide) }\end{array}$ & $\mathrm{C}_{10} \mathrm{H}_{16} \mathrm{O}_{2}$ & 168 & 5.25 \\
\hline 4 & 6.53 & 5-Isopropenyl-2-methyl-7-oxabicyclo[4.1.0]heptan-2-ol & $\mathrm{C}_{10} \mathrm{H}_{16} \mathrm{O}_{2}$ & 168 & 9.04 \\
\hline 5 & 9.13 & Cyclohexanol, 2-methyl-5-(1-methylethenyl)- & $\mathrm{C}_{10} \mathrm{H}_{18} \mathrm{O}$ & 154 & 0.93 \\
\hline 6 & 10.53 & 3,7,11,15-Tetramethyl-2-hexadecen-1-ol & $\mathrm{C}_{20} \mathrm{H}_{40} \mathrm{O}$ & 296 & 4.21 \\
\hline 7 & 10.98 & E-7-Tetradecenol & $\mathrm{C}_{14} \mathrm{H}_{28} \mathrm{O}$ & 212 & 2.51 \\
\hline 8 & 12.29 & Tetradecanoic acid & $\mathrm{C}_{14} \mathrm{H}_{28} \mathrm{O}_{2}$ & 228 & 22.43 \\
\hline 9 & 13.32 & 1-Hexadecanol & $\mathrm{C}_{16} \mathrm{H}_{34} \mathrm{O}$ & 242 & 3.92 \\
\hline 10 & 13.58 & Phytol & $\mathrm{C}_{20} \mathrm{H}_{40} \mathrm{O}$ & 296 & 3.00 \\
\hline 11 & 14.27 & 9,12-Octadecadienoic acid (Z,Z)- & $\mathrm{C}_{18} \mathrm{H}_{32} \mathrm{O}_{2}$ & 280 & 8.95 \\
\hline 12 & 17.07 & Octadecanoic acid, ethyl ester & $\mathrm{C}_{20} \mathrm{H}_{40} \mathrm{O}_{2}$ & 312 & 1.30 \\
\hline 13 & 19.14 & Didodecyl phthalate & $\mathrm{C}_{32} \mathrm{H}_{54} \mathrm{O}_{4}$ & 502 & 1.13 \\
\hline 14 & 22.57 & Squalene & $\mathrm{C}_{30} \mathrm{H}_{50}$ & 410 & 1.01 \\
\hline 15 & 29.35 & cis-Z- $\alpha$-Bisabolene epoxide & $\mathrm{C}_{15} \mathrm{H}_{24} \mathrm{O}$ & 220 & 4.68 \\
\hline
\end{tabular}

$R T$ Retention time

$M W$ Molecular weight

and structure of the components of the test materials were ascertained. A total of 15 components were identified (Fig. 1; Table 1), among them tetradecanoic acid $\left(\mathrm{C}_{14} \mathrm{H}_{28} \mathrm{O}_{2}\right)$ was the major component available at a $\mathrm{RT}$ of $12.29 \mathrm{~min}$ and with a peak area of $22.43 \%$, the second major component was 3-methoxysalicylic acid $\left(\mathrm{C}_{8} \mathrm{H}_{8} \mathrm{O}_{4}\right)$ with a RT of $4.88 \mathrm{~min}$ and $18.38 \%$ peak area. Further components were identified by GC-MS spectral comparison with the database NIST, including 
bicyclo[4.1.0] heptan-3-ol, 4,7,7-trimethyl- $(1 \alpha, 3 \alpha, 4 \alpha, 6 \alpha)-\left(\mathrm{C}_{10} \mathrm{H}_{18} \mathrm{O}\right) 4.10$ min RT, peak area $13.28 \%$, and 5-isopropenyl-2-methyl-7-oxabicyclo[4.1.0]heptan-2-ol $\left(\mathrm{C}_{10} \mathrm{H}_{16} \mathrm{O}_{2}\right) 6.53$ min $\mathrm{RT}$, peak area $9.04 \%$ (Table 1). It has been reported that tetracyclic triterpenoids showed activity on entomopathogenic nematodes [6], and tetradecanoic acid acted as a good larvicide and repellent against the dengue and yellow fever vector A. aegypti, while squalene has a variety of health-promoting functions, including tumor-suppressing [1, 94, 104, 119], antibacterial/antifungal [118], and cholesterol-lowering [76] effects. Also, squalene has recently attracted

(a)
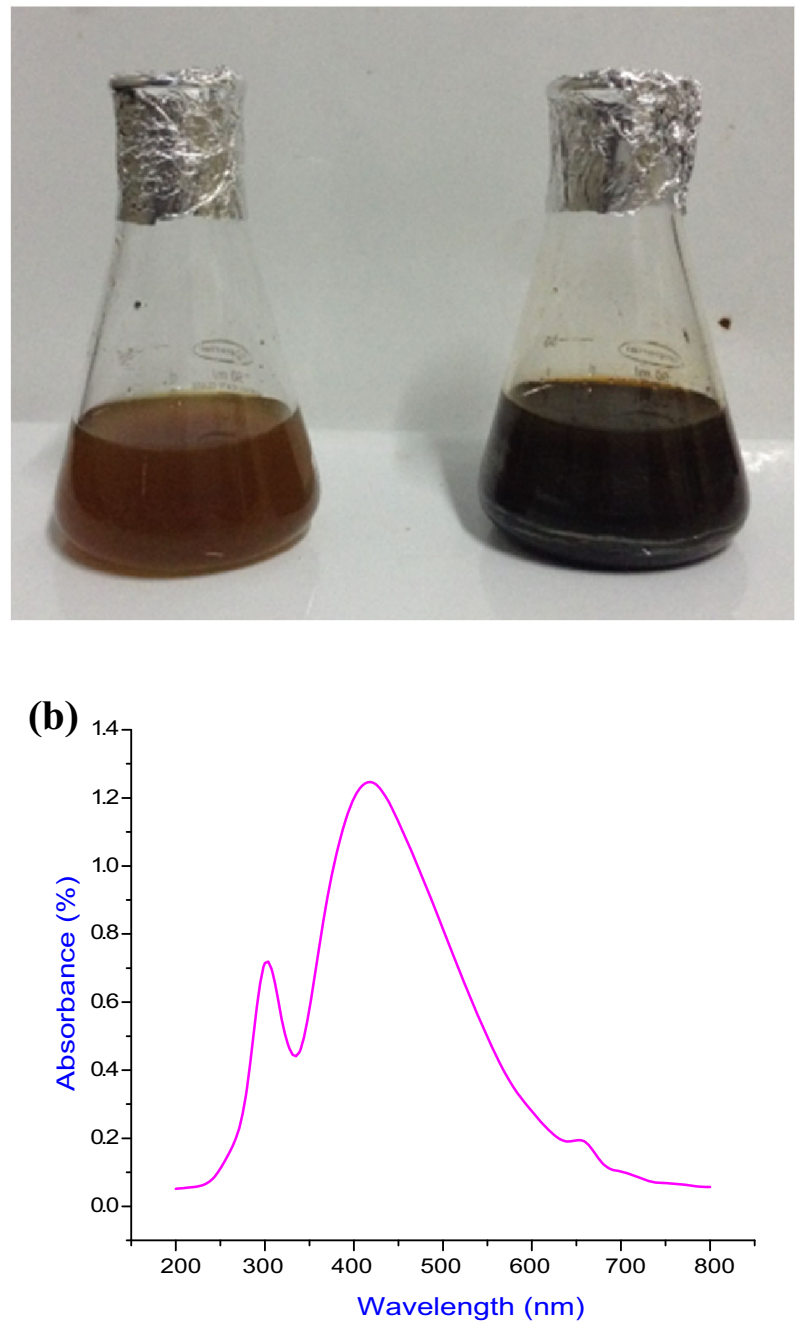

Fig. 2 a Chromatic variations of the aqueous leaf extract of Chenopodium ambrosioides before and after the process of reduction of $\mathrm{Ag}^{+}$to Ag nanoparticles. $\mathbf{b} \mathrm{UV}-\mathrm{Visualization}$ of the absorption spectrum of Ag nanoparticles synthesized using $C$. ambrosioides after $120 \mathrm{~min}$ from the reaction 
attention as a feasible source of biofuels [109]. The insecticidal properties of essential oils containing these compounds against several pest species, including mosquito vectors, have been reported by $[31,116,138]$.

\section{Characterization of Silver Nanoparticles}

In our experiments, UV-Vis spectrum showed a maximum absorbance peak at $421 \mathrm{~nm}$ which increased over time during the incubation of silver nitrate with the $C$. ambrosioides extract (Fig. 2). When the $\mathrm{AgNO}_{3}$ solution was added to the $C$. ambrosioides leaf extract, the color changed from light to dark brown, indicating the reduction from $\mathrm{Ag}^{+}$to $\mathrm{Ag}^{0}$ (Fig. 2a). The formation of AgNP was confirmed through the presence of an absorption peak at $421 \mathrm{~nm}$ (Fig. 2). Our UV-Vis results are in agreement with previous research $[66,82,107,115,127,137]$. The main peak detected here indicated a surface Plasmon resonance (SPR), which has been recorded for different metal nanoparticles ranging from 2 to $100 \mathrm{~nm}$ in size $[56,106]$.

TEM observations showed different shapes of $C$. ambrosioides-synthesized AgNP, including spherical, round and hexagonal ones, with mean size ranging from 25 to $50 \mathrm{~nm}$ (Fig. 3). Similarly, the morphological features of green synthesized silver, gold and metal nanoparticles fabricated using extracts from several terrestrial and marine plants, lead to mean nanoparticle sizes ranging from 15 to $70 \mathrm{~nm}$ (e.g. [82, 83, 103, 125, 127] Furthermore, C. ambrosioides-synthesized AgNP did not

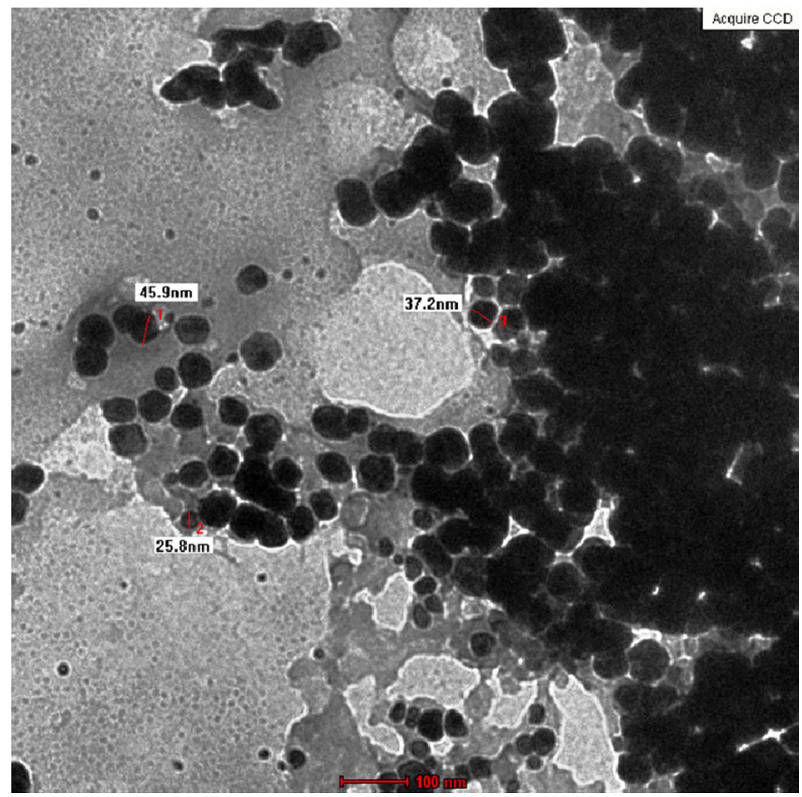

Fig. 3 Transmission electron microscopy (TEM) of green-synthesized silver nanoparticles obtained by reduction of $\mathrm{AgNO}_{3}$ with the leaf extract of Chenopodium ambrosioides 


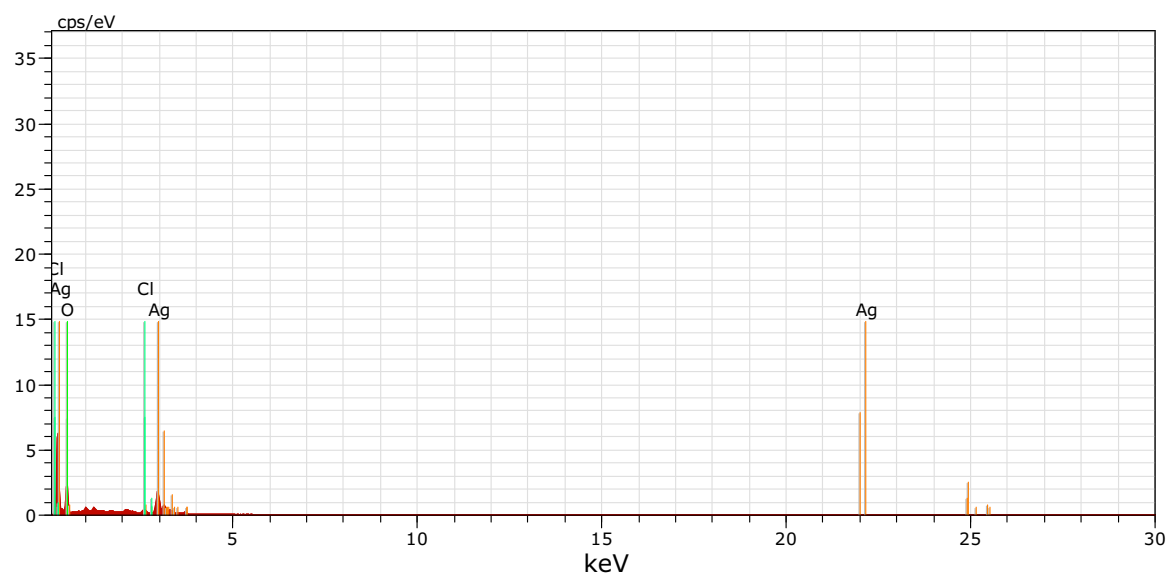

Fig. 4 Energy dispersive X-ray (EDX) profile of silver nanoparticles synthesized using the leaf extract of Chenopodium ambrosioides

show direct contact within aggregates, allowing us to argue that their stabilization occurred through capping agents.

The EDX spectrum recorded from C. ambrosioides synthesized AgNP revealed a distinct signal and high atomic percent values for Ag (Fig. 4). EDX analysis confirmed the presence of elemental Ag. The presence of oxygen (O) and silver (Ag) indicates that the extracellular organic compounds were adsorbed on the surface of AgNP (Fig. 4). The present finding corroborates previous reports on AgNP biosynthesis using botanical and microbial products [3, 43, 50-52, 67]. XRD patterns showed intense peaks corresponding to the (111), (200), (220), (311) and (222) sets of lattice planes (Fig. 5). The XRD patterns showed that the AgNP formed by the reduction of $\mathrm{AgNO}_{3}$ using $C$. ambrosioides leaf extract were crystalline in nature (Fig. 5). The XRD pattern observed in this study was consistent with previous reports [5, 48]. For instance, [111] reported diffraction peaks at $44.50^{\circ}, 52.20^{\circ}$, and $76.7^{\circ}=2 \theta$, which correspond to the (111), (200), and (220) facets of the face-centered cubic crystal structure.

FTIR spectroscopy was carried out to identify the possible biomolecules in the $C$. ambrosioides extract, which may be responsible for synthesis and stabilization of AgNP (Fig. 6). FTIR spectrum of AgNP prepared using the C. ambrosioides leaf extract showed peaks at 3431.36, 2362.80, 2063.83, 1633.71, 1514.12, 1456.26, and $418.55 \mathrm{~cm}^{-1}$ (Fig. 6). The peak located at about $2,362.80 \mathrm{~cm}^{-1}$ can be attributed to the $\mathrm{N}-\mathrm{H}$ stretching vibrations or the $\mathrm{C}=\mathrm{O}$ stretching vibrations. The sharp absorption peak at $1633.71 \mathrm{~cm}^{-1}$ may be assigned to $\mathrm{C}=\mathrm{O}$ stretching vibration in carbonyl compounds which may be characterized by the presence of high content of terpenoids and flavonoids. A broad intense band at $3,431.36 \mathrm{~cm}^{-1}$ in both leaf extract and AgNP spectra can be linked to the $\mathrm{N}-\mathrm{H}$ stretching frequency arising from the peptide linkages present in the proteins of the extract $[71,78]$. Therefore, it may be inferred that these biomolecules are responsible for capping and efficient stabilization of synthesized nanoparticles. Thus, the analysis of FTIR spectrum from 


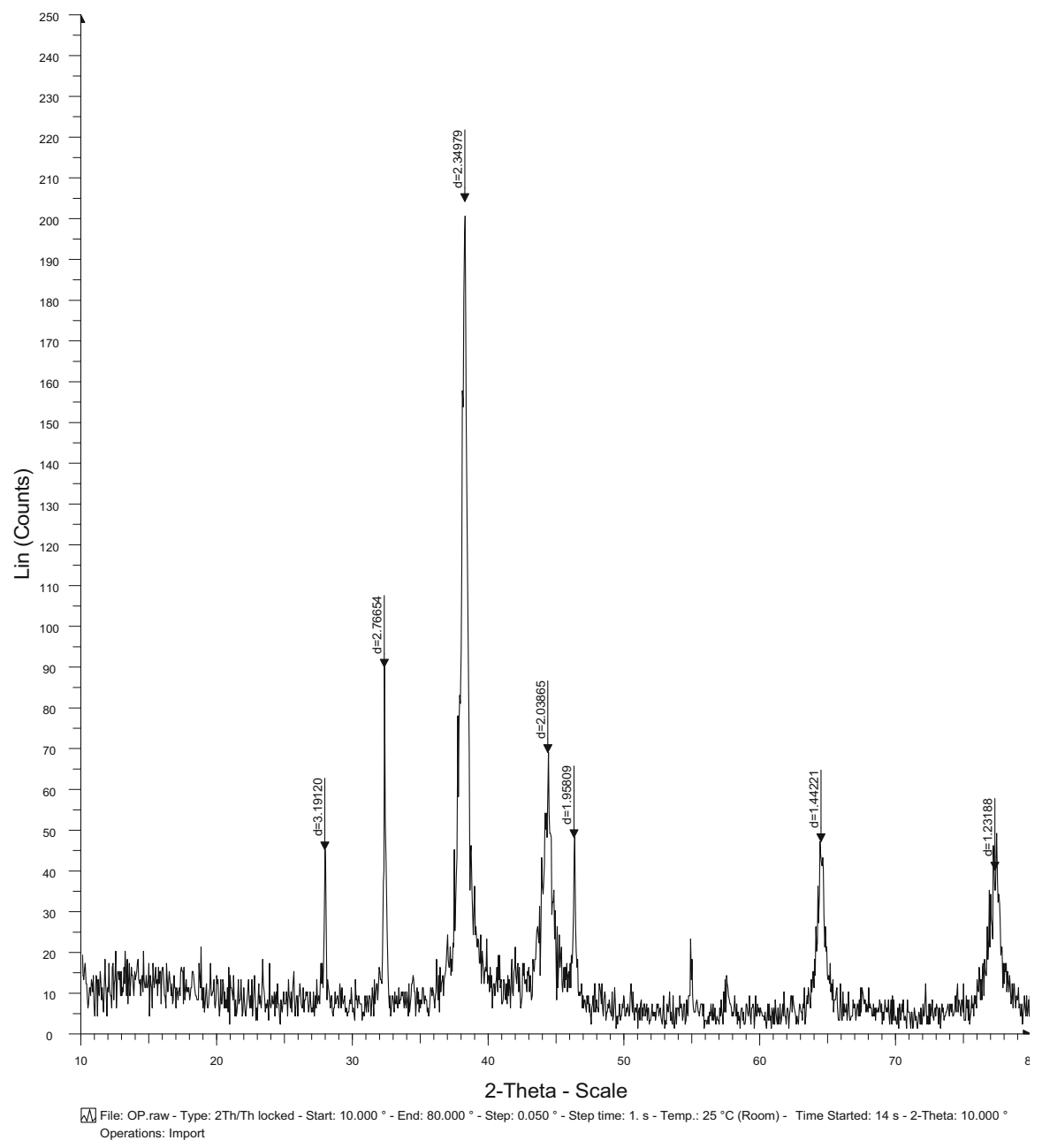

Fig. 5 X-ray diffraction pattern of silver nanoparticles synthesized using the leaf extract of Chenopodium ambrosioides

the green fabricated AgNP showed the presence of different functional groups from alkane, methylene, alkene, amine, and carboxylic acid, previously reported as reducing agents in the nano-biosynthesis [33]. Polyphenols have been also reported as potential reducing agent in the biosynthesis of $\mathrm{AgNP}[79,100]$. The adsorption on the surface of metal nanoparticles is a characteristic of flavanones and terpenoids, since they easily interacted through carbonyl groups in the lack of other strong ligating agents in sufficient concentration [113].

Particle size and size distribution are the most important characteristics of nanoparticle systems. In our analysis, zeta potential of AgNP was $-18.5 \mathrm{mV}$ (Fig. 7). Similarly, [42] noted that $C$. album-synthesized silver and gold nanoparticles were stable under a wide $\mathrm{pH}$ range due to their high zeta potential. In 


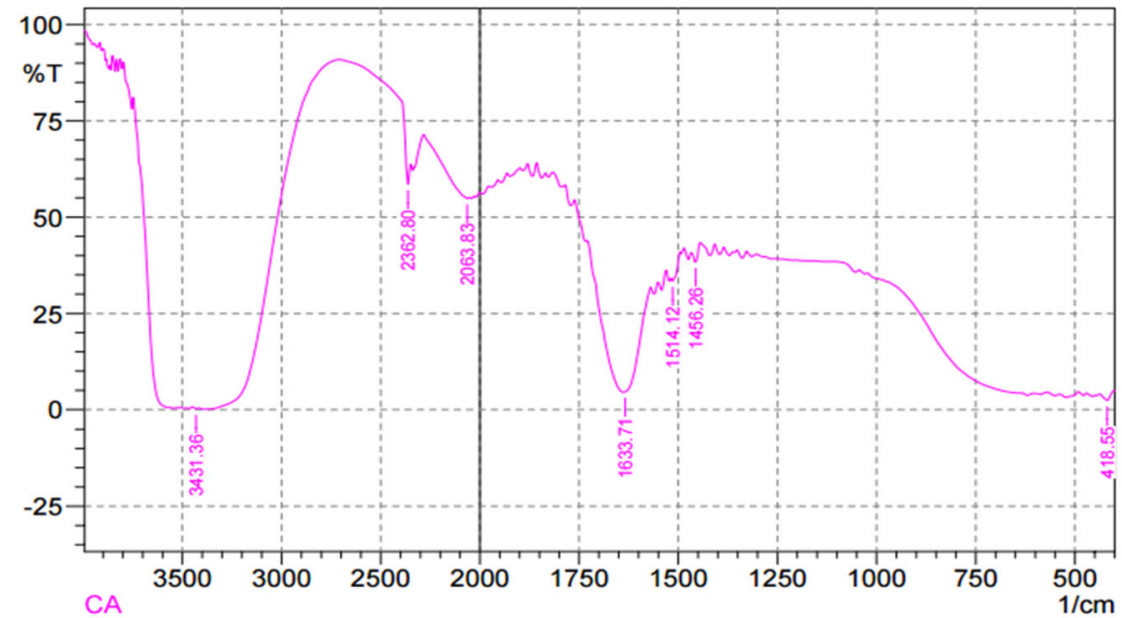

\begin{tabular}{|l|l|l|l|l|l|l|l|}
\hline No. & Peak & Intensity & Corr. Intensity & Base (H) & Base (L) & Area & Corr. Area \\
\hline 1 & 418.55 & 2.38 & 2.08 & 435.91 & 401.19 & 51.28 & 4.29 \\
\hline 2 & 1456.26 & 38.31 & 3.79 & 1467.83 & 1444.68 & 9.17 & 0.47 \\
\hline 3 & 1514.12 & 33.37 & 1.92 & 1517.98 & 1494.83 & 10.3 & 0.42 \\
\hline 4 & 1633.71 & 4.59 & 0.81 & 1635.64 & 1570.06 & 58.37 & -1.78 \\
\hline 5 & 2063.83 & 54.87 & 0.95 & 2283.72 & 2054.19 & 47.76 & 1.3 \\
\hline 6 & 2362.8 & 58.54 & 6.18 & 2713.84 & 2349.3 & 27.08 & -16.14 \\
\hline 7 & 3431.36 & 0.2 & 0.33 & 3446.79 & 3419.79 & 66.24 & 5.06 \\
\hline
\end{tabular}

Fig. 6 Fourier transform infrared spectroscopy (FTIR) of silver nanoparticles synthesized using the leaf extract of Chenopodium ambrosioides

$\begin{array}{rlllll} & & \text { Mean }(\mathrm{mV}) & \text { Area }(\%) & \text { Width }(\mathrm{mV}) \\ \text { Zeta Potential }(\mathrm{mV}): & -18.5 & \text { Peak 1: } & -18.5 & 100.0 & 5.08 \\ \text { Zeta Deviation }(\mathrm{mV}): & 5.08 & \text { Peak 2: } & 0.00 & 0.0 & 0.00 \\ \text { Conductivity }(\mathrm{mS} / \mathrm{cm}): & 0.364 & \text { Peak 3: } & 0.00 & 0.0 & 0.00\end{array}$

Result quality : Good

\section{Zeta Potential Distribution}

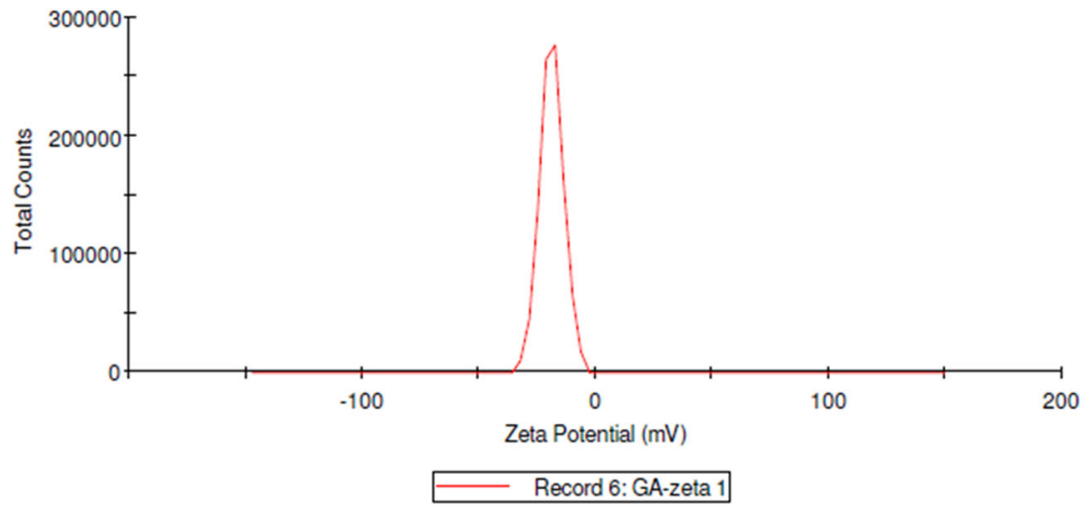

Fig. 7 Zeta potential analysis of silver nanoparticles synthesized using the leaf extract of Chenopodium ambrosioides 
agreement with TEM results, size analysis showed a distribution of particle diameters ranging from 10 to $90 \mathrm{~nm}$ with an average particle size of $25 \mathrm{~nm}$. The particle sizes determined the in vivo distribution, biological fate, toxicity and the targeting ability of nanoparticle systems [13]. [40] have reported that $100 \mathrm{~nm}$ nanoparticles had a 2.5 fold greater uptake than $1 \mu \mathrm{m}$ microparticles, and sixfold greater uptake than $10 \mu \mathrm{m}$ microparticles on Caco-2 cell line.

\section{Toxicity on Aedes albopictus}

In laboratory conditions, the $C$. ambrosioides ethanolic leaf extract showed larvicidal and pupicidal toxicity against $A$. albopoictus, with $\mathrm{LC}_{50}$ values ranging from $124.55 \mathrm{ppm}$ (I instar larva) to $237.06 \mathrm{ppm}$ (pupa), respectively (Table 2). A number of plant extracts has been reported as effective against larvae and pupae of mosquito vectors $[10,61,122,123]$. More recently, the green biosynthesis of mosquitocidal nanoparticles is advantageous over chemical and physical methods, since it is cheap, single-step, and does not require high pressure, energy, temperature, and the use of highly toxic chemicals [87, 102, 103]. In this study C. ambrosioides-synthesized AgNP were toxic against A. albopictus larvae and pupae, with $\mathrm{LC}_{50}$ values ranging from $13.37 \mathrm{ppm}$ (I instar) to $19.77 \mathrm{ppm}$ (pupa) (Table 3). In agreement with our data, [126] showed that Mimusops elengi leaf aqueous extract was moderately effective against malarial vector, Anopheles stephensi and arbovirus vector A. albopictus while the $\mathrm{LC}_{50}$ of $\mathrm{AgNP}$ fabricated using this plant and tested on A. stephensi ranged from 12.53 (I instar larvae) to $23.55 \mathrm{ppm}$ (pupae), and $\mathrm{LC}_{50}$ against A. albopictus ranged from $11.72 \mathrm{ppm}$ (I) to 21.46 ppm (pupae). Low doses of AgNP biosynthesized using Euphorbia hirta leaf extract have been reported as highly toxic against $A$. stephensi, withLC $\mathrm{C}_{50}$ values

Table 2 Acute toxicity of Chenopodium ambrosioides leaf extract on young instars of the dengue and Zika virus vector, Aedes albopictus

\begin{tabular}{|c|c|c|c|c|c|}
\hline \multirow[t]{2}{*}{ Target } & \multirow[t]{2}{*}{$\mathrm{LC}_{50}\left(\mathrm{LC}_{90}\right)$} & \multicolumn{2}{|c|}{$95 \%$ Confidence limit $\mathrm{LC}_{50}\left(\mathrm{LC}_{90}\right)$} & \multirow[t]{2}{*}{ Regression equation } & \multirow{2}{*}{$\begin{array}{l}\chi^{2} \\
(d . f .=4)\end{array}$} \\
\hline & & Lower & Upper & & \\
\hline Larva I & $124.55(335.30)$ & $93.76(305.61)$ & $148.35(376.65)$ & $y=0.757+0.006 x$ & 1.10 n.s \\
\hline Larva II & $143.24(398.83)$ & $108.83(359.33)$ & $169.68(457.24)$ & $y=0.718+0.005 x$ & $1.11 \mathrm{n} . \mathrm{s}$ \\
\hline Larva III & $172.10(453.72)$ & $138.95(404.76)$ & $198.68(529.22)$ & $y=0.783+0.005 x$ & 0.44 n.s \\
\hline Larva IV & $199.55(488.86)$ & $169.34(434.44)$ & $225.68(573.88)$ & $y=0.884+0.004 x$ & $1.55 \mathrm{n} . \mathrm{s}$ \\
\hline Pupa & $237.06(554.90)$ & $207.60(485.72)$ & $266.14(668.54)$ & $y=0.956+0.004 x$ & 1.72 n.s \\
\hline
\end{tabular}

No mortality was observed in the control

$L C_{50}$ lethal concentration that kills $50 \%$ of the exposed organisms

$L C_{90}$ lethal concentration that kills $90 \%$ of the exposed organisms

$\chi^{2}$ Chi square value

d.f. degrees of freedom

n.s. not significant $(\alpha=0.05)$ 
Table 3 Acute toxicity of Chenopodium ambrosioides-synthesized silver nanoparticles on young instars of the dengue and Zika virus vector Aedes albopictus

\begin{tabular}{lcccccc}
\hline Target & $\mathrm{LC}_{50}\left(\mathrm{LC}_{90}\right)$ & \multicolumn{2}{l}{$95 \%$ Confidence limit LC $50\left(\mathrm{LC}_{90}\right)$} & Regression equation & $\begin{array}{l}\chi^{2} \\
(d . f .=4)\end{array}$ \\
\cline { 3 - 5 } & & \multicolumn{2}{c}{ Lower } & Upper & & \\
\hline Larva I & $13.37(37.05)$ & $9.53(33.81)$ & $16.29(41.49)$ & $y=0.724+0.054 x$ & $4.89 \mathrm{n} . \mathrm{s}$ \\
Larva II & $14.44(39.42)$ & $10.59(35.96)$ & $17.38(44.20)$ & & $y=0.741+0.051 x$ & $3.78 \mathrm{n} . \mathrm{s}$ \\
Larva III & $15.41(46.34)$ & $10.78(41.80)$ & $18.85(53.02)$ & & $Y=0.639+0.041 x$ & $0.62 \mathrm{n} . \mathrm{s}$ \\
Larva IV & $17.39(51.19)$ & $12.70(45.84)$ & $20.90(59.30)$ & & $y=0.660+0.038 x$ & $1.22 \mathrm{n} . \mathrm{s}$ \\
Pupa & $19.77(60.66)$ & $14.48(53.12)$ & $23.69(73.18)$ & $y=0.620+0.031 x$ & $0.49 \mathrm{n} . \mathrm{s}$ \\
\hline
\end{tabular}

No mortality was observed in the control

$L C_{50}$ lethal concentration that kills $50 \%$ of the exposed organisms

$L C_{90}$ lethal concentration that kills $90 \%$ of the exposed organisms

$\chi^{2}$ Chi square value

d.f. degrees of freedom

n.s. not significant $(\alpha=0.05)$

ranging from $10.14 \mathrm{ppm}$ (I instar larvae) to $34.52 \mathrm{ppm}$ (pupae) [101]. Another good example is the larvicidal activity of Leucas aspera-synthesized AgNP, with $\mathrm{LC}_{50}$ ranging from 13.06 to $25.54 \mathrm{ppm}$ for $A$. aegypti, and from 12.45 to $22.26 \mathrm{ppm}$ for $A$. stephensi [117]. Nelumbo nucifera-synthesized AgNP were toxic to the larvae of $A$. subpictus $\left(\mathrm{LC}_{50}=0.69 \mathrm{ppm}\right)$ and $C$. quinquefasciatus $\left(\mathrm{LC}_{50}=1.10 \mathrm{ppm}\right.$; $\mathrm{LC}_{90}=3.59 \mathrm{ppm}$ ), respectively [110]. In the field, the application of C. ambrosioides aqueous extract and $C$. ambrosioides-synthesized $\mathrm{AgNP}\left(10 \times \mathrm{LC}_{50}\right)$ in water storage reservoirs led to the complete elimination of larval populations of $A$. albopictus after $72 \mathrm{~h}$ (Table 4). [104] reported that the stable neem fractions were as effective as mosquito larvicides in the field. Plant based insecticides have been evaluated successfully in different habitats of mosquito vectors, tested species include Clerodendron inerme, Acanthus ilicifolius [63], M. elengi and greensynthesized AgNP [125], Phyllanthus niruri and green-synthesized AgNP [128]. Further research aimed to clarify the exact mechanism(s) of action of AgNP against mosquito young instars is ongoing [13].

In adulticidal experiments, the $C$. ambrosioides leaf extract and green-synthesized AgNP were toxic to A. albopictus (Table 5). LC $_{50}$ values were $154.99 \mathrm{ppm}$ (C. ambrosioides extract) and $14.29 \mathrm{ppm}(\mathrm{AgNP})$. At the highest concentration tested, the adults of both species remained still for a short time period (i.e. 1-3 min) following application, showed fast wagging movements and then died. The adulticidal efficacy of a number of plant borne extracts and essential oils against adult mosquitoes of public health importance has been reported by several recent studies (e.g. [2, 97, 123, 125, 126]. For example, Subramaniam al. [125] reported that the adulticidal activity of methanol extracts of seaweeds D. dichotoma, $P$. pavonica and $V$. pachynema on the costal malarial vector Anopheles sundaicus, $\mathrm{LC}_{50}$ values were $147.18 \mathrm{ppm}, 161.94 \mathrm{ppm}$ and $133.79 \mathrm{ppm}$, respectively. On Ae. 


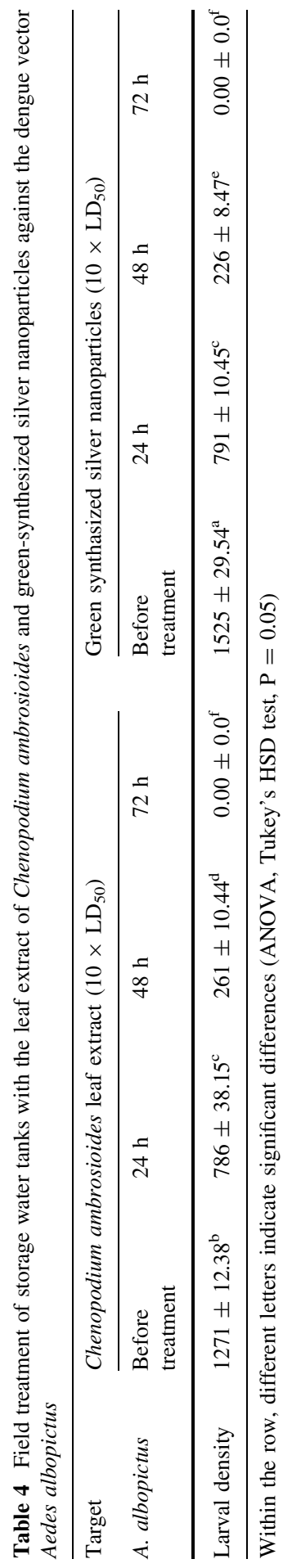




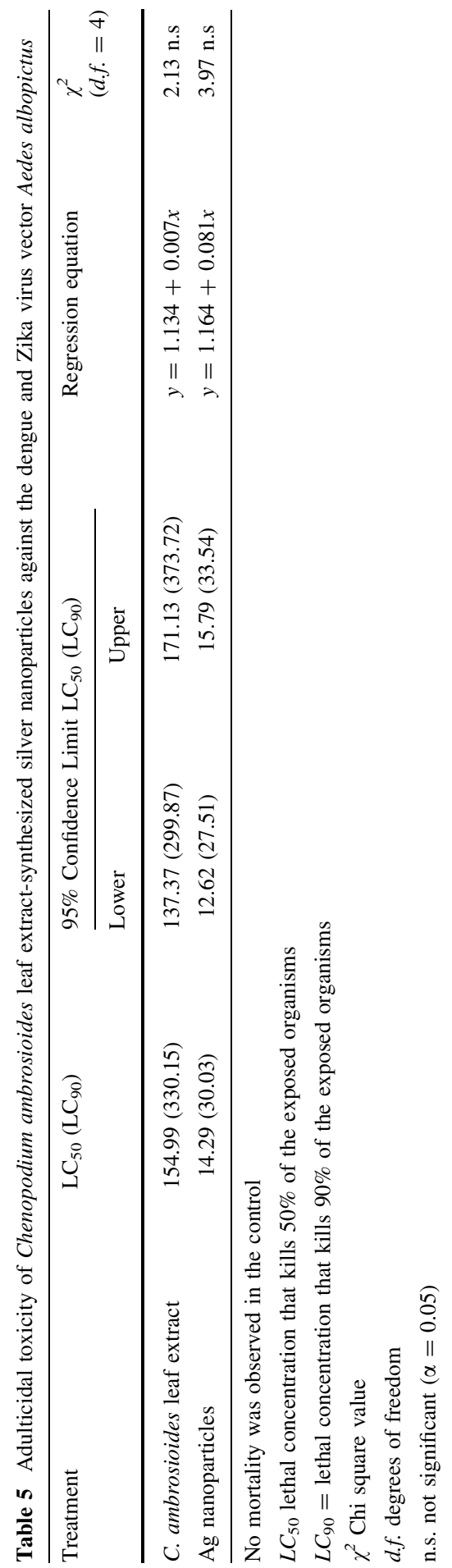


aegypti, an high adulticidal effect was reported for Piper sarmentosum, followed by Piper ribesoides and Piper longum, with $\mathrm{LD}_{50}$ values of $0.14,0.15$ and 0.26 microg/ female, respectively [36]. [49] have reported that the adulticidal activity was observed testing the methanol extracts of E. alba and A. paniculata on An. stephensi, $\mathrm{LC}_{50}$ and $\mathrm{LC}_{90}$ values were of $150.36,130.19 \mathrm{ppm}$ and 285.22 , and 244.16 ppm respectively. Besides this interesting data, few efforts have been done to shed light on the contact toxicity of green-fabricated AgNP on mosquito adults [11]. We hypothesized that an important toxicity effect can be due to the magnified action of bioactive botanicals capping the wide surfaces of the nanocomposite.

\section{Impact of Ag nanoparticles on Oryzias melastigma predation}

Biological control of mosquito larval populations using aquatic predators, such as insects, fishes, copepods, and tadpoles recently received renewed attention (e.g. $[19,81-85,126,127]$; see [17] for a review). In this present study, the rice fish, $O$. melastigma showed high predation rates on the dengue vector A. albopictus $2^{\text {nd }}$ and $3^{\text {rd }}$ instar larvae post-treatment with very low doses of AgNP. In standard conditions, after $24 \mathrm{~h}$, the predation rates of II and III instar larvae of A. albopictus were 65.5 and $59.0 \%$. Predation by $O$. melastigma post-treatment with ultra-low dosages of $C$. ambrosioides aqueous extract were 75.0 and $83.0 \%$, while posttreatment with green-synthesized AgNP reached 91.0 and $85.5 \%$ against II and III instar larvae, resepctively (Table 6). No detectable toxicity effects were observed on O. melastigma individuals exposed to the AgNP-contaminated aquatic environment (post-treatment observation period: 10 days; data not shown). In agreement with our data, previous studies testing other aquatic species, including Gambusia affinis [28, 126];), Hoplobatrachus tigerinus [84], Poecilia reticulata [85], Aplocheilus lineatus [127], Carassius auratus (Linneaus) [29], Xenontodon cancila [27], Ctenopharyngodon idella, Cyprinus carpio [30], Oreochromis niloticus niloticus

Table 6 Predation efficiency of Oryzias melastigma fishes against Aedes albopictus larvae in standard laboratory conditions and post-treatment with sub-lethal doses of the leaf extract of Chenopodium ambrosioides-fabricated silver nanoparticles

\begin{tabular}{lllllll}
\hline Treatment & Target & \multicolumn{2}{l}{ Exposure time } & \multicolumn{2}{l}{$\begin{array}{l}\text { Total } \\
\text { predation } \\
\text { per fish (\%) }\end{array}$} \\
\cline { 3 - 6 } & & $0-6 \mathrm{~h}$ & $6-12 \mathrm{~h}$ & $12-18 \mathrm{~h}$ & $18-24 \mathrm{~h}$ & \\
\hline Control & Larva II & $30 \pm 1.41$ & $32 \pm 2.54$ & $35 \pm 1.22$ & $34 \pm 2.23$ & $65.5^{\mathrm{d}}$ \\
& Larva III & $29 \pm 1.41$ & $31 \pm 1.58$ & $29 \pm 2.34$ & $28 \pm 1.22$ & $59.0^{\mathrm{e}}$ \\
C. ambrosioides extract & Larva II & $43 \pm 2.16$ & $40 \pm 2.94$ & $41 \pm 1.41$ & $42 \pm 0.81$ & $83.0^{\mathrm{bc}}$ \\
& Larva III & $38 \pm 0.70$ & $37 \pm 2.12$ & $36 \pm 1.22$ & $39 \pm 2.34$ & $75.0^{\mathrm{c}}$ \\
Silver nanoparticles & Larva II & $46 \pm 1.58$ & $43 \pm 1.87$ & $46 \pm 1.73$ & $47 \pm 1.22$ & $91.0^{\mathrm{a}}$ \\
& Larva III & $43 \pm 2.94$ & $41 \pm 2.16$ & $42 \pm 2.08$ & $45 \pm 2.21$ & $85.5^{\mathrm{b}}$ \\
\hline
\end{tabular}

Predation rates are mean $\pm \mathrm{SD}$ of five replicates (1 fish vs. 200 mosquitoes per replicate/day)

Control was clean water without fishes

Within the column, values followed by different letters are significantly different (generalized linear model, $\mathrm{P}<0.05)$ 
[25, 46], Betta splendens, Pseudotropheus tropheops tropheops, Osphronemus goramy Lacépède, and Pterophyllum scalare [45], showed good predatory ability on mosquito larvae under similar testing conditions. Recently, Chobua et al. [34] studied $G$. affinis and $C$. auratus as control agents of $A$. gambiae. In addition, our data, in agreement with recent researches [54, 58, 88, 126, 127], highlighted the limited toxicity of plant extracts and green nanocomposites on mosquito natural enemies, as well as the chance to use both tools in synergy to successfully manage mosquito young instar populations.

\section{Conclusions}

Overall, in the present work we reported the synthesis of AgNP at room temperature using the aqueous extract of $C$. ambrosioides, and their high toxicity against larvae, pupae and adults of the invasive mosquito A. albopictus. It is worthy to note that extremely low doses of the reducing extract and AgNP magnify the predation rates of $O$. melastigma fishes against $A$. albopictus 2 nd and 3rd instar larvae, highlighting the concrete potential of $C$. ambrosioides-synthesized AgNP to develop effective and cheap tools to control young instars and adults of the invasive mosquito $A$. albopictus.

Acknowledgements Two anonymous reviewers kindly improved an earlier version of our manuscript. J. Subramaniam is grateful to the Science and Engineering Research Board (SERB), Department of Science and Technology (DST), New Delhi, India for the financial support (Principal Investigator/NPDFDST-SERB/Project File n. PDF/2015/000650).

\section{Compliance with Ethical Standards}

Conflicts of interest The Authors declare no conflicts of interest.

Research Involving Human and Animal Rights All applicable international and national guidelines for the care and use of animals were followed. All procedures performed in studies involving animals were in accordance with the ethical standards of the institution or practice at which the studies were conducted.

\section{References}

1. A. Aioi, T. Shimizu, and K. Kuriyama (1995). Int. J. Pharm. 113, 159.

2. D. Amerasan, K. Murugan, K. Kovendan, P. M. Kumar, C. P. Selvam, J. Subramaniam, S. John William, and J. S. Hwang (2012). Parasitol. Res 111, 1953.

3. D. Amerasan, T. Nataraj, K. Murugan, P. Madhiyazhagan, C. Panneerselvam, M. Nicoletti, and G. Benelli (2016). J. Pest Sci. 89, 249.

4. A. Azizullah, Z. U. Rehman, I. Ali, W. Murad, N. Muhammad, W. Ullah, and D.-P. Hader (2014). Parasitol. Res 113, 4321.

5. H. Bar, K. R. Dipak Bhui, P. Gobinda Sahoo, and P. Sarkar (2009). Coll. Surf. A. Physicochem. Eng. Asp. 339, 134.

6. M. E. Barbercheck and J. Wang (1996). J. Insect. Pathol. 68, (2), 141.

7. S. K. Batabyal, C. Basu, A. R. Das, and G. S. Sanyal (2007). J. Biobased Mater. Bioenerg. 1, 143.

8. N. A. Begum, S. Mondal, S. Basu, R. A. Laskar, and D. Mandal (2009). Coll. Surf. B 71, 113.

9. G. Benelli (2015). Parasitol. Res 114, 2801. 
10. G. Benelli (2015). Parasitol. Res 114, 3201.

11. G. Benelli (2016). Parasitol. Res 115, 23.

12. G. Benelli (2016). Asia Pacif. J. Trop. Biomed. 6, 353.

13. G. Benelli (2016). Enzyme. Microb. Technol. doi:10.1016/j.enzmictec.2016.08.022.

14. G. Benelli and H. Mehlhorn (2016). Parasitol. Res 115, 1747.

15. G. Benelli, A. Lo Iacono, A. Canale, and H. Mehlhorn (2016). Parasitol. Res 115, 2131.

16. G. Benelli, R. Pavela, A. Canale, and H. Mehlhorn (2016). Parasitol. Res. doi:10.1007/s00436-0165095-1.

17. G. Benelli, C. L. Jeffries, and T. Walker (2016). Insects. 7, 52.

18. S. Bhatt, P. W. Gething, and O. J. Brady (2013). Nature. 496, 504.

19. G. Bowatte, P. Perera, G. Senevirathne, S. Meegaskumbura, and M. Meegaskumbura (2013). Biol. Control 67, 469.

20. O. J. Brady, P. W. Gething, S. Bhatt, J. P. Messina, J. S. Brownstein, and A. G. Hoen (2012). PLoS Negl. Trop. Dis. 6, e1760. doi:10.1371/journal.pntd.0001760.

21. L. J. Bruce-Chwatt (1985). Drugs Exp. Clin. Res 11, 899.

22. S. D. Caruthers, S. A. Wickline, and G. M. Lanza (2007). Curr. Opin. Biotech. 18, 26.

23. A. M. Carvalho Plantasy sabiduria popular del Parque Natural de Montesinho. Un estudio etnobotanico en Portugal. Biblioteca de Ciencias, 35 (Consejo Superior de Investigaciones Cientıficas, Madrid, 2010).

24. J. F. Cavalli, F. Tomi, A. F. Bernardini, and J. Casanova (2004). Phytochem Anal 15, 275.

25. S. K. Chand and R. S. Yadav Use of Oreochromis mossambicus (Peters) in controlling mosquito breeding in cow dung pits. in V. P. Sharma and A. Ghosh (eds.), Larvivorous Fishes of Inland Ecosystems (Malaria Research Centre, Delhi, 1994), p. 115.

26. G. Chandra, I. Bhattacharjee, S. N. Chatterjee, and A. Ghosh (2008). Indian J. Med. Res 127, 13.

27. S. N. Chatterjee and G. Chandra (1996). Environ. Ecol. 14, 173.

28. S. N. Chatterjee and G. Chandra (1997). Sci. Cult. 63, 51.

29. S. N. Chatterjee, S. Das, and G. Chandra (1997). Transact. Zool. Soc. India 1, 112.

30. S. N. Chatterjee, A. Ghosh, and G. Chandra (2001). Transact. Zool. Soc. India 5, 83.

31. S. S. Cheng, J. Y. Liu, K. H. Tsai, W. J. Chen, and S. T. Chang (2004). J. Agric. Food Chem. 52, 4395.

32. L. Cheryl, T. Nancy, B. Gerhard, L. Grant, and G. Karla (2006). J. Ethnobiol. Ethnomed. doi:10. 1186/1746-4269-2-31.

33. K. Cho, J. Park, T. Osaka, and S. Park (2005). Electrochim. Acta 51, 956.

34. M. Chobua, G. Nkwengulilaa, A. M. Mahandeb, B. J. Mwang'ondeb, and J. E. Kwekab (2015). Acta. Trop. 142, 131.

35. K. Y. Choi, G. Liu, S. Lee, and X. Chen (2012). Nanoscale. 4, 330.

36. W. Choochote, U. Chaithong, K. Kamsuk, E. Rattanachanpichai, A. Jitpakdi, P. Tippawangkosol, D. Chaiyasit, D. Champakaew, B. Tuetun, and B. Pitasawat (2006). Rev. Inst. Med. Trop. S. Paulo. 48, 33.

37. A. Costello, T. Dua, P. Duran, M. Gülmezoglu, O. T. Oladapo, W. Perea, J. Pires, P. R. Pardo, N. Rollins, and S. Saxena (2016). Bull. World Health Organ 94, 406. doi:10.2471/BLT.16.176990.

38. G. V. B. Cruz, P. V. S. Pereira, F. J. Patricio, G. C. Costa, S. M. Sousa, J. B. Frazao, W. C. AragaoFilho, M. C. G. Maciel, Amaral F. M. M. SilvaLA, E. S. B. Barroqueiro, R. N. M. Guerra, and F. R. F. Nascimento (2007). J. Ethnopharmacol. 111, 148.

39. M. R. Das, R. K. Sarma, R. Saikia, V. S. Kale, M. V. Shelke, and P. Sengupta (2011). Coll. Surf. B 83, 16.

40. M. P. Desai, V. Labhasetwar, E. Walter, R. J. Levy, and G. L. Amidon (1997). Pharm. Res 14, 1568.

41. D. Dinesh, K. Murugan, P. Madhiyazhagan, C. Panneerselvam, M. Nicoletti, W. Jiang, G. Benelli, B. Chandramohan, and U. Suresh (2015). Parasitol. Res 114, 1519.

42. A. D. Dwivedi and K. Gopal (2010). Coll. Surf. A. 369, (2010), 27.

43. A. M. Fayaz, K. Balaji, Y. R. GirilalM, P. T. Kalaichelvan, and R. Venketesan (2010). Nanomed. Nanotechnol. Biol. Med. 6, 103.

44. D. J. Finney Probit Analysis (Cambridge University Press, London, 1971), p. 68.

45. A. Ghosh, I. Bhattacharjee, M. Ganguly, S. Mandal, and G. Chandra (2004). Bull. Penelit. Kesehat. 32, 144.

46. A. Ghosh, I. Bhattacharjee, and G. Chandra (2006). J Appl Zool Res 17, 114. 
47. A. P. Goncalvez, R. E. Engle, M. St Claire, R. H. Purcell, and C. J. Lai (2007). Proc. Natl. Acad. Sci. USA. 104, 9422.

48. P. Gong, H. Li, X. He, K. Wang, J. Hu, W. Tan, S. Zhang, and X. Yang (2007). Nanotechnology. 18, 285604.

49. M. Govindarajan and R. Sivakumar (2011). Asia. Pacif. J. Trop. Med. 4, (1), 941.

50. M. Govindarajan and G. Benelli (2016). Parasitol. Res 115, 925.

51. M. Govindarajan and G. Benelli (2016). RSC. Adv. 6, 59021.

52. M. Govindarajan and G. Benelli (2016). J. Clust. Sci. doi:10.1007/s10876-016-1035-6.

53. M. M. Green and J. M. Singer (1981). J. Am. Mosq. Control Assoc. 7, 282.

54. K. M. Haldar, B. Haldar, and G. Chandra (2013). Parasitol. Res 112, 1451.

55. J. Hemingway and H. Ranson (2000). Annu. Rev. Entomol. 45, 371.

56. A. Henglein (1993). J. Phys. Chem. 97, 5457.

57. J. Huang, G. Zhan, B. Zheng, D. Sun, F. Lu, and Y. Lin (2011). Ind. Eng. Chem. Res 50, 9095.

58. A. Jaganathan, K. Murugan, C. Panneerselvam, P. Madhiyazhagan, D. Dinesh, C. Vadivalagan, A. T. Aziz, B. Chandramohan, U. Suresh, R. Rajaganesh, J. Subramaniam, M. Nicoletti, A. Higuchi, A. A. Alarfaj, M. A. Munusamy, S. Kumar, and G. Benelli (2016). Parasitol. Int. 65, 276.

59. Y. S. Jang, M. K. Kim, Y. S. Ahn, and H. S. Lee (2002). Agric. Chem. Biotechnol. 4, 131.

60. K. C. Jayaram The Freshwater Fishes of India, Pakistan, Bangladesh, Burma and Sri Lanka (ZSI, Calcutta, 1981).

61. M. Kalyanasundaram and P. K. Das (1985). Indian. J. Med. Res 82, 19.

62. E. G. Kamel, M. A. El-Emam, S. S. M. Mahmoud, F. M. Fouda, and F. E. Bayaumy (2011). Parasitol. Int. 60, 388.

63. K. Kovendan and K. Murugan (2011). Adv. Environ. Biol. 5, 335.

64. A. T. Le, P. T. Huy, P. D. Tam, T. Q. Huy, P. D. Cam, and A. A. Kudrinskiy (2010). Curr. Appl. Phys. 10, 910.

65. V. Louca, M. C. Lucas, C. Green, S. Majambere, U. Fillinger, and S. W. Lindsay (2009). J. Med. Entomol. 46, 546.

66. P. Madhiyazhagan, K. Murugan, A. Naresh Kumar, T. Nataraj, D. Dinesh, C. Panneerselvam, J. Subramaniam, P. Mahesh Kumar, U. Suresh, M. Roni, M. Nicoletti, A. A. Alarfaj, A. Higuchi, M. A. Munusamy, and G. Benelli (2015). Parasitol. Res. doi:10.1007/s00436-015-4671-0.

67. P. Magudapathy, P. Gangopadhyay, B. K. Panigrahi, K. G. M. Nair, and S. Dhara (2001). Physica 299, 142.

68. A. K. Manna (1989). Environ. Ecol. 7, 502.

69. A. K. Manna and S. Bannerjee (1984). Sci. Cult. 50, 329.

70. A. K. Manna and S. Bannerjee (1985). Environ. Ecol. 3, 456.

71. S. Marimuthu, A. A. Rahuman, G. Rajakumar, T. Santhoshkumar, A. Vishnu Kirthi, C. Jayaseelan, A. Bagavan, A. Abduz Zahir, G. Elango, and C. Kamaraj (2011). Parasitol. Res 108, 1541.

72. McClelland (1839) http://www.marinespecies.org/aphia.php?p=taxdetails\&id=315132.

73. A. G. K. Menon Indigenous Larvivorous Fishes of India (NIMR, New Delhi, 1991).

74. H. Mehlhorn (ed.) Encyclopedia of Parasitology, 4th ed (Springer, New York, 2015).

75. H. Mehlhorn, K. A. Al-Rasheid, S. Al-Quraishy, and F. Abdel-Ghaffar (2012). Parasitol. Res 110, 259.

76. T. A. Miettinen and H. Vanhanen (1994). Am. J. Clin. Nutr. 59, 356.

77. Mishra A (2002) Evaluation of some higher plant products for their pesticidal activity against some storage fungi and insects. Ph D thesis. Banaras Hindu University, Varanasi, India.

78. P. Mukherjee, M. Roy, B. P. Mandal, G. K. Dey, P. K. Mukherjee, J. Ghatak, A. K. Tyagi, and S. P. Kale (2008). Nanotechnology 19, 075103.

79. K. S. Mukunthan, E. K. Elumalai, T. N. Patel, and V. R. Murty (2011). Asian Pac. J. Trop. Biomed. 1, 270 .

80. K. Murugan, V. Vahitha, I. Baruah, and S. C. Das (2003). Ann. Med. Entomol. 12, 11.

81. K. Murugan, J. S. Hwang, K. Kovendan, K. Prasanna Kumar, C. Vasugi, and A. Naresh Kumar (2011). Hydrobiologia 666, 331.

82. K. Murugan, N. Aarthi, K. Kovendan, C. Panneerselvam, B. Chandramohan, P. M. kumar, D. Amerasan, M. Paulpandi, R. Chandirasekar, D. Dinesh, U. Suresh, J. Subramaniam, A. Higuchi, A. A. Alarfaj, M. Nicoletti, H. Mehlhorn, and G. Benelli (2015). Parasitol. Res 114, 3657.

83. K. Murugan, C. M. Samidoss, C. Panneerselvam, A. Higuchi, M. Roni, U. Suresh, B. Chandramohan, J. Subramaniam, P. Madhiyazhagan, D. Dinesh, R. Rajaganesh, A. A. Alarfaj, M. 
Nicoletti, S. Kumar, H. Wei, A. Canale, H. Mehlhorn, and G. Benelli (2015). Parasitol. Res 114, 4087.

84. K. Murugan, V. Priyanka, D. Dinesh, P. Madhiyazhagan, C. Panneerselvam, J. Subramaniam, U. Suresh, B. Chandramohan, M. Roni, M. Nicoletti, A. A. Alarfaj, A. Higuchi, M. A. Munusamy, H. F. Khater, R. H. Messing, and G. Benelli (2015). Parasitol. Res. doi:10.1007/s00436-015-4582-0.

85. K. Murugan, J. S. E. Venus, C. Panneerselvam, S. Bedini, B. Conti, M. Nicoletti, S. K. Sarkar, J. S. Hwang, J. Subramaniam, P. Madhiyazhagan, P. M. Kumar, D. Dinesh, U. Suresh, and G. Benelli (2015). Environ. Sci. Poll. Res. doi:10.1007/s11356-015-4920-x.

86. K. Murugan, M. Aamina Labeeba, C. Panneerselvam, D. Dinesh, U. Suresh, J. Subramaniam, P. Madhiyazhagan, J. S. Hwang, L. Wang, M. Nicoletti, and G. Benelli (2015). Res. Vet. Sci. 102, 127.

87. K. Murugan, P. Aruna, C. Panneerselvam, P. Madhiyazhagan, M. Paulpandi, J. Subramaniam, R. Rajaganesh, H. Wei, M. Saleh Alsalhi, Nicoletti M. DevanesanS, B. Syuhei, A. Canale, and G. Benelli (2016). Parasitol. Res 115, 651.

88. K. Murugan, J. Anitha, D. Dinesh, U. Suresh, R. Rajaganesh, B. Chandramohan, J. Subramaniam, M. Paulpandi, C. Vadivalagan, P. Amuthavalli, L. Wang, J. S. Hwang, H. Wei, M. S. Alsalhi, S. Devanesan, S. Kumar, K. Pugazhendy, A. Higuchi, M. Nicoletti, and G. Benelli (2016). Ecotoxicol. Environ. Saf 132, 318.

89. K. Murugan, C. Panneerselvam, A. T. Aziz, J. Subramaniam, P. Madhiyazhagan, J. S. Hwang, Lan Wang, D. Dinesh, U. Suresh, M. Roni, A. Higuchi, M. Nicoletti, M. Saleh Alsalhi, and G. Benelli (2016). Environ. Sci. Poll. Res. doi:10.1007/s11356-016-6832-9.

90. K. Murugan, D. Nataraj, P. Madhiyazhagan, V. Sujitha, B. Chandramohan, C. Panneerselvam, D. Dinesh, R. Chandirasekar, K. Kovendan, U. Suresh, J. Subramaniam, M. Paulpandi, C. Vadivalagan, R. Rajaganesh, H. Wei, B. Syuhei, A. T. Aziz, M. Saleh Alsalhi, S. Devanesan, M. Nicoletti, A. Canale, and G. Benelli (2016). Parasitol. Res 115, 1071.

91. M. N. Naqqash, A. Gökçe, A. Bakhsh, and M. Salim (2016). Parasitol. Res 115, 1363.

92. F. R. F. Nascimento, G. V. B. Cruz, P. V. S. Pereira, M. C. G. Maciel, L. A. Silva, A. P. S. Azevedo, E. S. B. Barroqueiro, and R. N. M. Guerra (2006). Life Sci. 78, 2650.

93. S. Navaladian, B. Viswanathan, R. P. Viswanath, and T. K. Varadarajan (2007). Nanoscale Res. Lett. 2, 44.

94. H. L. Newmark (1997). Cancer Epidemiol Biomark Prev. 6, 1101.

95. M. Nicoletti, S. Mariani, O. Maccioni, T. Coccioletti, and K. Murugan (2012). Parasitol. Res 111, 205.

96. S. Y. Ohba, Dida G. O. KawadaH, D. Juma, G. Sonye, N. Minakawa, and M. Takagi (2010). J. Med. Entomol. 47, 783.

97. C. Panneerselvam and K. Murugan (2013). Parasitol Res 112, (2), 679.

98. C. Panneerselvam, K. Murugan, M. Roni, A. T. Aziz, U. Suresh, R. Rajaganesh, P. Madhiyazhagan, J. Subramaniam, D. Dinesh, M. Nicoletti, A. Higuchi, A. A. Alarfaj, M. A. Munusamy, S. Kumar, N. Desneux, and G. Benelli (2016). Parasitol. Res 115, 997.

99. R. Pavela and G. Benelli (2016). Tr Plant Sci. doi:10.1016/j.tplants.2016.10.005.

100. T. N. V. K. V. Prasad and E. K. Elumalai (2011). Asian Pac. J. Trop. Biomed. 1, 439.

101. A. Priyadarshini, K. Murugan, C. Panneerselvam, S. Ponarulselvam, H. Jiang Shiou, and M. Nicoletti (2012). Parasitol. Res 111, 997.

102. G. Rajakumar and A. A. Rahuman (2011). Acta Trop. 118, 196.

103. R. Rajan, K. Chandran, S. L. Harper, S. I. Yun, and P. T. Kalaichelvan (2015). Ind. Crops Prod. 70, 356.

104. C. V. Rao, H. L. Newmark, and B. S. Reddy (1998). Carcinogenesis. 19, 287.

105. J. V. Rao and P. Kavitha (2010). Z Naturforsch. C. 65, 303.

106. B. K. Ravindra and A. H. Rajasab (2014). Int. J. Pharm. Pharm. Sci. 6, 372.

107. M. Roni, K. Murugan, C. Panneerselvam, J. Subramaniam, M. Nicoletti, P. Madhiyazhagan, D. Dinesh, U. Suresh, H. F. Khater, H. Wei, Alarfaj A. A. CanaleA, M. A. Munusamy, A. Higuchi, and G. Benelli (2015). Ecotoxicol. Environ. Saf. doi:10.1016/jecoenv201507005.

108. D. E. Rosen and L. R. Parenti (1981). Am. Mus. Novit. 27, 1.

109. M. A. Rude and A. Schirmer (2009). Curr. Opin. Microbiol. 12, 274.

110. T. Santhoshkumar, A. A. Rahuman, G. Rajakumar, S. Marimuthu, A. Bagavan, C. Jayaseelan, A. A. Zahir, G. Elango, and C. Kamaraj (2010). Parasitol. Res 108, 693.

111. R. Sathyavathi, M. Balamurali Krishna, S. Venugopal Rao, R. Saritha, and D. Narayana Rao (2010). Adv. Sci. Lett. 3, 1.

112. Service MW (1977). J. Med. Entomol. 13, 535. 
113. S. S. Shankar, A. Rai, A. Ahmad, and M. Sastry (2004). J. Coll. Interf. Sci. 275, 496.

114. V. P. Sharma and A. Ghosh Larvivorous Fishes of Inland Ecosystem (NIMR, New Delhi, 1994).

115. B. P. Singh, B. J. Hatton, B. Singh, A. L. Cowie, and A. Kathuria (2010). J. Environ. Qual. 39, 1.

116. R. Sivakumar, A. Jebanesan, M. Govindarajan, and P. Rajasekar (2011). Asia. Pacif. J. Trop. Med. 2011, 706.

117. S. Sivapriyajothi, P. Mahesh Kumar, K. Kovendan, J. Subramaniam, and K. Murugan (2014). J. Entomol. Acarol. Res 46, 1787.

118. T. J. Smith (2000). Exp. Opin. Invest. Drugs. 9, 1841.

119. T. J. Smith, G. Y. Yang, D. N. Seril, J. Liao, and S. Kim (1998). Carcinogenesis. 19, (4), 703.

120. K. S. Sreeram, M. Nidin, and B. U. Nair (2008). Bull. Mater. Sci. 31, 937.

121. M. Starowicz, B. Stypuła, and J. Banas (2006). Electrochem. Commun. 8, 227.

122. J. Subramaniam, K. Murugan, and K. Kovendan (2012). J. Biopestic. 5, 163.

123. J. Subramaniam and M. Murugan (2013). Evaluation of larvicidal, pupicidal, repellent, and adulticidal activity of Myristica fragrans (Family: Myristicaceae) against malarial vector Anopheles stephensi. Proceedings of the national conference on insect diversity and systematics: special emphasis on molecular approaches. pp:1-6.

124. J. Subramaniam and K. Murugan (2014). J. Int. J. Biol. Sci. 2014, 33.

125. J. Subramaniam, K. Murugan, K. Kovendan, P. M. Kumar, D. Amerasan, C. P. Selvam, T. Nataraj, D. Dinesh, B. Chandramohan, R. Chandrasekar, and J. S. Hwang (2015). Util. Manag. Med. Plants. 3, 261.

126. J. Subramaniam, K. Murugan, C. Panneerselvam, K. Kovendan, P. Madhiyazhagan, P. M. Kumar, D. Dinesh, B. Chandramohan, U. Suresh, M. Nicoletti, A. Higuchi, J. S. Hwang, S. Kumar, A. A. Alarfaj, M. A. Munusamy, R. H. Messing, and G. Benelli (2015). Environ. Sci. Poll. Res 22, (24), 20067.

127. J. Subramaniam, K. Murugan, C. Panneerselvam, K. Kovendan, P. Madhiyazhagan, D. Dinesh, P. Mahesh Kumar, B. Chandramohan, U. Suresh, R. Rajaganesh, Mohamad Saleh Alsalhi, S. Devanesan, M. Nicoletti, A. Canale, and G. Benelli (2016). Environ. Sci. Pollut. Res. doi:10.1007/ s11356-015-6007-0.

128. U. Suresh, K. Murugan, G. Benelli, M. Nicoletti, D. R. Barnard, C. Panneerselvam, P. Mahesh Kumar, J. Subramaniam, D. Dinesh, and B. Chandramohan (2015). Parasitol. Res 114, 1551.

129. G. Taubes (2000). Science. 290, (5491), 434.

130. S. Thiripura and S. Shankar (2014). Int. J. Pharm. Tech. Res 6, 1731.

131. A. Voyadjoglou, V. Roussis, and P. V. Petrakis Biological control of mosquito populations: an applied aspect of pest control by means of natural enemies. in A. M. T. Elewa (ed.), Predation in Organisms: Adistinct Phenomenon (Springer, Berlin, 2007), p. 123.

132. W. W. Walton (2007). J. Am. Mosq. Control Assoc. 23, (S2), 184.

133. WHO (1981) Instructions for determining the susceptibility or resistance of adult mosquitoes to organochlorine, organophosphate and carbamate insecticides: diagnostic test. WHO/VBC/81-807, Geneva.

134. WHO (2015) Dengue and severe dengue. Fact sheet $\mathrm{N}^{\circ} 117$. World Health Organization, Geneva.

135. WHO (2016) Weekly epidemiological record, No 7, 19 Feb 2016, Vol. 91, 73-88.

136. H. Yap (1985). Southeast Asian J. Trop. Med. Public Health. 16, 163.

137. M. Zargar, A. A. Hamid, F. A. Bakar, M. N. Shamsudin, K. Shameli, F. Jahanshiri, and F. Farahani (2011). Molecules. 6, 6667.

138. J. Zhu, X. Zeng, M. O. Neal, G. Schultz, B. Tucker, and J. Coats (2008). J. Am. Mosq. Control. Assoc. 24, 161. 